Review

\title{
Hyperspectral and Chlorophyll Fluorescence Imaging for Early Detection of Plant Diseases, with Special Reference to Fusarium spec. Infections on Wheat
}

\section{Elke Bauriegel * and Werner B. Herppich}

Leibniz Institut für Agrartechnik Potsdam-Bornim, Max-Eyth-Allee 100, D-14469 Potsdam, Germany; E-Mail:wherppich@atb-potsdam

* Author to whom correspondence should be addressed; E-Mail: ebauriegel@atb-potsdam; Tel.: +49-331-5699-629; Fax: +49-331-5699-849.

Received: 7 February 2014; in revised form: 11 March 2014 / Accepted: 17 March 2014 / Published: 24 March 2014

\begin{abstract}
In recent years, market pressures have reinforced the demand to solve the problem of an increased occurrence of Fusarium head blight (FHB) in cereal production, especially in wheat. The symptoms of this disease are clearly detectable by means of image analysis. This technique can therefore be used to map occurrence and extent of Fusarium infections. From this perspective, a separate harvest in the field can be taken into consideration. Based on the application of chlorophyll fluorescence and hyperspectral imaging, characteristics, requirements and limitations of Fusarium detection on wheat, both in the field and in the laboratory, are discussed. While the modification of spectral signatures due to fungal infection allows its detection by hyperspectral imaging, the decreased physiological activity of tissues resulting from Fusarium impacts provides the base for CFI analyses. In addition, the two methods are compared in view of their usability for the detection of Fusarium, and different approaches for data analysis are presented.
\end{abstract}

Keywords: head blight; differentiated spatial analysis; imaging; Triticum spp.; quality and safety of cereals

\section{Introduction}

The aim of modern agriculture is it not only to increase and optimize production but also to produce safe and healthy food and feed of high quality. In this regard, especially Fusarium infections on cereals 
represent an important, increasingly growing problem. Fusarium promoting cultivation systems such as intensified maize production have considerably aggravated the problem in recent years. Consequently, the extent of Fusarium infection has increased worldwide. Yield losses of up to 30\% [1] may highlight the tremendous impact of this disease.

Typical early and externally visible symptoms of Fusarium infections are the bleaching of individual spikelets and the partial dieback of the ear or head well before maturity. These symptoms are eponymous for the name of this fungal disease: "head blight". The direct consequence of Fusarium infection is a massive crop failure due to the final development of shrunken lowmass tombstone kernels. The worst problem of the disease, however, is the potential toxic side effect due to the production of mycotoxins. Highly contaminated lots of grain are evidentially harmful and dangerous to humans and livestock. Fusarium generates mycotoxins such as deoxinivalenol (DON), zearalenone and fumonisins to different degrees [2-4], which can cause vomiting, mass loss, kidney failure, miscarriage, false pregnancy and cancer [5-9].

Therefore, infected grains should always be excluded from the human food cycle or livestock feed. In this context, identification of Fusarium infestations in the field with simple and rapid methods would be a substantial progress in food and feed safety. This might offer producers the opportunity to separately harvest infected and healthy grains, which, in turn avoids the risk of mixing contaminated and non-infected lots for storage. Separate harvest is also appropriate because spread of Fusarium fungi and synthesis of mycotoxins can proceed under certain conditions in storage. In addition, the risk of mycotoxin toxication of food can be decreased and the rational use of the Fusarium infected grain facilitated.

Until now, rapid and comprehensive Fusarium detection methods are not available in practice. It is still common to test grain lots for a possible mycotoxin contamination namely to determine their content of mycotoxin only at harvest or post-harvest. For this purpose, time consuming and expensive laboratory tests are necessary (HPLC, serological rapid tests, Fast-DON-ELISA-test, counting method [10]).

Along the entire cereal production chain, there are various options and management practices to avoid Fusarium infection and, thus, the occurrence of head blight (Figure 1). First of all, Fusarium tolerant wheat cultivars should be chosen for cultivation. In crop rotation, cereals such as maize, wheat, barley of durum, which readily spread Fusarium may be exclude, if possible. Furthermore, tillage may eliminate infected grain stubble or straw, which may function as inoculums the next year. This also prevents hibernation of fungi spores and, hence, a rapid distribution in the following spring. If disease pressure is high, e.g., due to unfavourable climatic conditions, fungicide must be applied shortly prior to flowering. At this time, azoles are often prophylactically sprayed on the entire field to assure prevention of Fusarium infection. Without doubt, closely targeted application of fungicides may be economically and ecologically advantages. This, however, requires routinely pre harvest acquisition of exact knowledge about the true, site-specific state of Fusarium infection.

Thus, automated reliable Fusarium detection is urgently needed because the frequency of infections is increasing, and, as a consequence, the legal provisions are intensified. Producers are waiting for innovative detection methods and appliances. Although currently not applied by default in crop production, such knowledge may be yet obtained by field monitoring with several recent imaging techniques. This review introduces the means of both chlorophyll fluorescence (CFI) and hyperspectral 
imaging for rapid site-specific on-field detection of head blight. It also presents recent advances in these techniques and discusses their capabilities and limits for practical applications of these methods.

Figure 1. Options to prevent Fusarium infection in the cereal production chain.

\section{Process chaln cereal productlon}

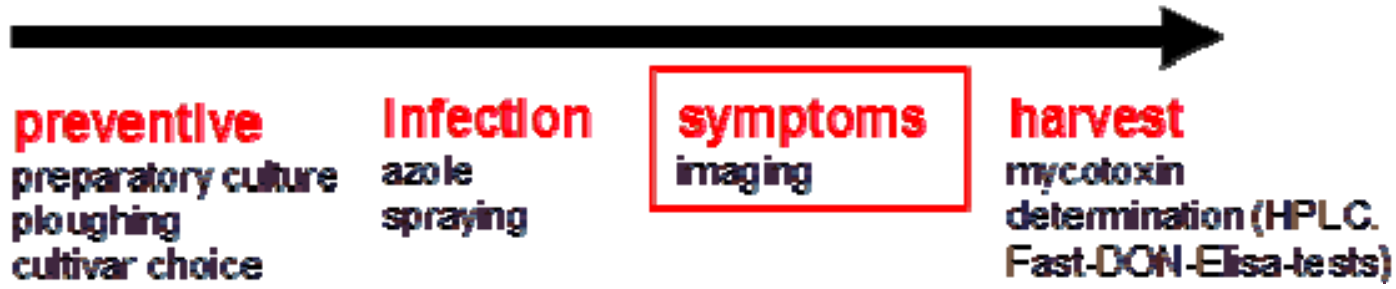

\section{Imaging Techniques to Detect Head Blight Symptoms}

During initial successful infection, Fusarium induces various internal changes and host-specific responses in inoculated plants. The resulting disease symptoms do normally not occur immediately but become externally visible only after approx. 7-11 days after inoculation. Only then, these symptoms can be detected and analyzed with spectro-optical reflectance measurements in the visible (VIS) and near-infrared (NIR) range $[11,12]$ but also with the aid of fluorescence spectroscopy. External, and to a certain degree also host-internal biochemical changes of cuticle, cell-walls, epidermis cells etc. changes may be evaluated by fluorescence and NIR measurements. In addition, fungal impacts on specific tissue properties such as composition and overall contents of leaf pigments or changes in cell water, sugar or protein contents may be investigated by remission measurements in the VIS and the NIR range, respectively. On the other hand, Fusarium effects on hosts' metabolic competence at the cellular level at progressing infection not necessarily develop externally visible symptoms. These plant responses can be, not least, comprehensively monitored by analyzing chlorophyll fluorescence transients, which, among others, reflect the integrity of the photosynthetic apparatus [13,14].

\subsection{Chlorophyll Fluorescence Imaging for Evaluation of Fungal Infections}

Chlorophyll fluorescence analysis (CFA; e.g., [13,14] and chlorophyll fluorescence imaging (CFI; e.g., $[15,16])$ are well-established, effective tools for a comprehensive examination of development and effects of bacterial, fungal and viral infections on leaves of many cultivated plants [17-20]. It can be used for entire intact plants $[21,22]$, detached leaves and also leaf disks punched out from infected plant material [23-25].

On wheat, CFI was applied to determine, among others, effects of drought and heat stress [26,27], of limited supply of nutrients [28] and of various diseases such as leaf rust [22,29], leaf and glume blotch [30] or powdery mildew [31].

For disease detection, the empirical fluorescence parameter $F_{v} / F_{0}$ has been proposed for use on dark adapted plants [29]. Although a clear physiological derivation is still lacking [32], $\mathrm{F}_{\mathrm{v}} / \mathrm{F}_{0}$ presumably represents the maximum quantum yield of fluorescence [33]. This parameter has been used as an indicator of the photosystem II (PSII) status and may estimate rates of energy transport from PSII to PSI in low-temperature fluorescence $\left(-196{ }^{\circ} \mathrm{C}\right.$; [34]). 
In addition, the potential maximum quantum yield of electron flow through completely open PSII, $F_{v} / F_{m}[34]$ is often used for evaluation of microbial diseases [16,20,24]. $F_{v} / F_{m}$ reflects the maximum photochemical efficiency and the interference with different environmental factors and may also indicate potential pathogen-related functional disturbance of the photosynthetic apparatus $[13,14]$. Fusarium infections immediately impact $\mathrm{F}_{\mathrm{v}} / \mathrm{F}_{\mathrm{m}}$ because the fungi rapidly and strongly impair metabolism and, thus, photosynthetic processes of contaminated spikelets or head parts of the host plants. The mycotoxins produced by the fungi may also contribute to the complete reduction of photosynthetic performance as has been found for infection of maize and banana by Colletotrichum musae and Fusarium moniliforme, respectively [35]. Hence, it has been shown that the reduction of $F_{v} / F_{m}$, and also $F_{v} / F_{0}$ [29], correlates closely with the degree of infection and is, therefore, a suitable parameter for detection of head blight and other fungal diseases [36].

\subsubsection{Advantages of Image Analyses}

Standard handheld Fluorometer, available from many various companies (e.g., Heinz Walz GmbH, Effeltrich, Germany; Hansatech Instruments Ltd., Norfolk, UK; Photon Systems Instruments, Brno, Czech Republic; Opti-Sciences Inc., Hudson, NY, USA; EARS Holding B.V., Delft, The Netherlands) provide average chlorophyll fluorescence values measured at a certain point of the examined object. In an attempt to identify tulip breaking virus (TBV) infections on three tulip cultivars with different leaf colour patterns, [37] analyzed average $F_{v} / F_{m}$ values, taken as precisely and as early as possible under laboratory conditions. Nonetheless, disease responses obtained by averaging $F_{v} / F_{m}$ over the entire leaves differed up to $46 \%$ from the degree of disease determined by ELISA-tests. It seems obvious that both spot measurements and averaging of the fluorescence parameter might level off most of the disease-related differences in photosynthetic responses [21].

Applying chlorophyll fluorescence imaging, [38] analyzed the spatial variation of disease development within infected wheat heads instead of averaging the chlorophyll fluorescence values over the entire object. This approach allows the close evaluation of even minor changes in the typical infection pattern of head blight. During disease development, the relative area of the heads with impacted spikelets and, hence, low $\mathrm{F}_{\mathrm{v}} / \mathrm{F}_{\mathrm{m}}(<0.3)$ increased, while that of healthy spikelets with high $\mathrm{F}_{\mathrm{v}} / \mathrm{F}_{\mathrm{m}}(>0.3)$ declined. Hence, spatial distribution patterns and not average chlorophyll fluorescence parameters were used to evaluate changes in the degree of disease during progressing infection. Pixel-wise classification of all $\mathrm{F}_{\mathrm{v}} / \mathrm{F}_{\mathrm{m}}$ in relatively small value class and class-wise accumulation of all $\mathrm{F}_{\mathrm{v}} / \mathrm{F}_{\mathrm{m}}$, starting from 0 up to a value of 0.3 facilitated the detection of the head blight disease. The degree of disease was even differentiable in 10\%-steps. Instead of leveling the infection-related differences by averaging the $F_{v} / F_{m}$ values, considerable differences between healthy and infected plants emerged by application of this approach. In addition, mathematical operations were easy to program and numerical efficient, which is essential for field application.

\subsubsection{The Timeframe of Detection}

Because it closely reflects the physiology of photosynthesis, chlorophyll fluorescence imaging enables the early detection of Fusarium infection-related tissue damage. It is, indeed, well established that variations in photosynthetic activity and in the chlorophyll fluorescence patterns are detectable at 
early stages of infection [29,39]. However, the earliest changes on a cellular level had only a minor effect on PSII $[38,40]$. Only when the integrity of cellular structures of host plants was damaged by the fungi, the photosynthetic system was impaired. This interpretation reflects findings of [41] and [42]. With light and electron microscopy, these authors showed that the dominating fungal hyphae caused pronounced cellular changes (e.g., degeneration of cytoplasm, destruction of cell organelles, disintegration of cell walls and deposition of cell wall material at the walls of vascular elements of the diseased head) only 4 to 5 days after infection.

However, the capability of chlorophyll fluorescence analysis and imaging, respectively, to detect fungal infections does not only depend on the period after inoculation; it is also considerably influenced by the object to examine itself. Infections by Pseudomonas syringae in Arabidopsis thaliana are detectable within few hours after inoculation [32]. In contrast, $F_{v} / F_{0}$ decreased two to three days before leaf rust and mildew infections, respectively, became visible on leaves of winter wheat [19]. Pustules of leaf rust appeared 6 days after inoculation (dai), while symptoms of mildew were visible approx. from the 9th dai onward. With leaf rust infection, $\mathrm{F}_{\mathrm{v}} / \mathrm{F}_{0}$ significantly declined by about 0.4 relative units after the 6th dai onward, while decreases in $\mathrm{F}_{\mathrm{v}} / \mathrm{F}_{\mathrm{m}}$ were considerably smaller ( 0.02 relative unit) compared to uninfected controls. First symptoms of Venturia inaequalis infection on apple seedlings could be detected at the 7th onward [43]. In seedlings of common spruce (Picea abies), needle rust (Chrysomyxa rhododendri) infections could be identified with CFA only three weeks after infection but not at earlier stage [44].

Time range for the meaningful detection of Fusarium infections of wheat with CFA and CFI is also limited. With the onset of wheat head maturation, chlorophyll content of the spikelets inevitably declines, and, concomitantly, also $\mathrm{F}_{\mathrm{v}} / \mathrm{F}_{\mathrm{m}}$ decreases irrespective of whether infected or not (Figure 2). Consequently, relative cumulative $F_{v} / F_{m}$ rapidly increases at low $F_{v} / F_{m}$ classes (Figure 2a). Logically, this parameter is no longer suitable for biunique disease detection on fully mature wheat heads (cf. dai $43=\mathrm{BBCH} 89$ ) after reaching the final grain developmental stage (BBCH 79; developed by Biologische Bundesanstalt für Land- und Forstwirtschaft, Bundessortenamt und Chemische Industrie, this system comprehensively describes development states of crops according to Eucarpia Codes, EC).

Figure 2. (a) Relative cumulative $\mathrm{F}_{\mathrm{v}} / \mathrm{F}_{\mathrm{m}}$ of a healthy wheat head during maturation. Measurements started from early fruit development (BBCH 71 at the 4th dai) and continued until final grain ripening $\left(\mathrm{BBCH} 89 ; 43 \mathrm{rd}\right.$ dai); (b) cumulative $\mathrm{F}_{\mathrm{v}} / \mathrm{F}_{\mathrm{m}}$ at 0.3 of a healthy and an inoculated wheat head during the course of the experiment
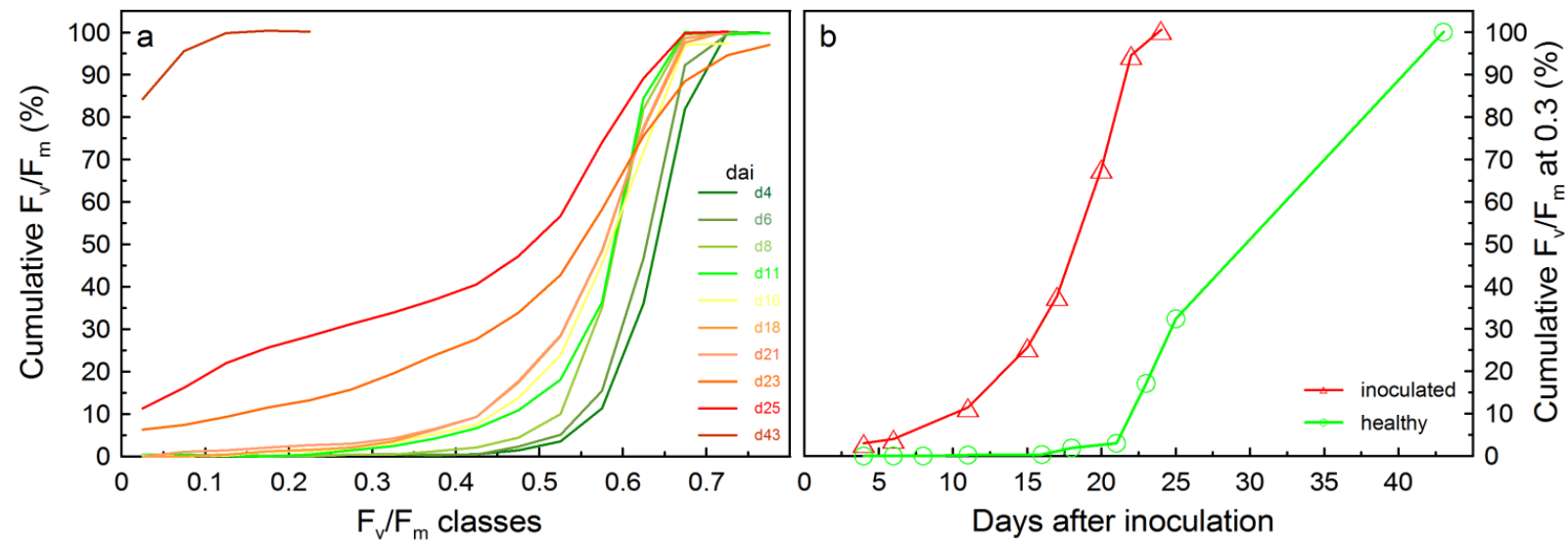


\subsubsection{Detection Accuracy of CFI on Wheat Plants with Different Degrees of Fusarium Infection}

The potential maximum photochemical efficiency $\mathrm{F}_{\mathrm{v}} / \mathrm{F}_{\mathrm{m}}$ readily indicates damage of photosynthetic apparatus by Fusarium culmorum. Very high detection accuracy (10\% RMSE) could be achieved with the application of the relative cumulative $\mathrm{F}_{\mathrm{v}} / \mathrm{F}_{\mathrm{m}}\left(\mathrm{rcF}_{\mathrm{v}} / \mathrm{F}_{\mathrm{m}}\right)$ at a threshold of 0.3 (Figure 2b) [38]. Relative cumulative $\mathrm{F}_{\mathrm{v}} / \mathrm{F}_{\mathrm{m}}$ values in the lower efficiency classes gradually increased from $<0.1 \%$ at $2 \%-3 \%$ of visually evaluated degrees of Fusarium infection (degrees of infection, doi) to $10 \%$ at doi of $10 \%-20 \%$, hold approx. $30 \%$ at degrees of infection of $40 \%-60 \%$ and reach $85 \%$ at an infection rate of $90 \%$. In the above investigation, averaging $\mathrm{F}_{\mathrm{v}} / \mathrm{F}_{\mathrm{m}}$ over the analysed heads indeed levelled all these differences. However, the application of distinct $F_{v} / F_{m}$ value classes precisely monitored the damaging effects of Fusarium on photosynthesis. Beyond a minimum doi of 5\%, the respective degrees of infection could be readily distinguished in steps of $10 \%$ with this method [38]. In other investigations [19,37], where all efficiency classes were considered by averaging, changes in $F_{v} / F_{m}$ with progressive infection remained small and could be only insufficiently resolved.

For practical application, the true degree of infection may be easily evaluated by remote CFI and use of relative cumulative $F_{v} / F_{m}$. With the threshold relative cumulative $F_{v} / F_{m}$ of 0.3 , the degree of infection contaminated wheat plants can be reliable estimated with only an error of 5.8\% $\left(\right.$ doi $\left.(\%)=4.00+1.073 \times \mathrm{rcF}_{\mathrm{v}} / \mathrm{F}_{\mathrm{m}} ; R^{2}=0.98\right)$.

\subsubsection{Application under Field Conditions}

The application of CFI for detection of fungal diseases under field conditions was occasionally tested [37,45-47]. For this purpose, [46] used a 10 bit-camera with a resolution of 1300 pixels $\times$ 1000 pixels, coupled with a four band optical beam splitter, pass-band filter (450, 550, 690 and $740 \mathrm{~nm})$, xenon arc lamp with IR cut-off filter and a low-pass filter (threshold at $410 \mathrm{~nm}$; emission spectral range 350-420 nm), while [48] used a chlorophyll fluorescence imaging system patented by [49].

In this regard, recording of steady state fluorescence signals is certainly easier than that of fluorescence kinetics [46]. [36] prefer $\phi_{\text {PSII }}\left(F_{q}{ }^{\prime} / F_{m}{ }^{\prime}=\left(F_{m}{ }^{\prime}-F_{t}\right) / F_{m}{ }^{\prime}\right)$ as an "extremely useful parameter" to measure $\mathrm{CF}$ under real environmental conditions. Without doubt, this parameter does not require any pre-darkening of the measured object. However, $\phi_{\text {PSII }}$ strongly depends on the highly variable prevailing daylight conditions, and should, therefore, be related to a certain standard. Because of their complex physiological nature, fluorescence signals directly depend on the regarding photosynthetic photon fluence rates [14]. In addition, values of light-adapted steady state fluorescence signals $\left(\mathrm{F}_{0}{ }^{\prime}, \mathrm{F}_{\mathrm{m}}\right)$ are lower than dark-adapted $\left(\mathrm{F}_{0}, \mathrm{~F}_{\mathrm{m}}\right)$ and measurable changes caused by the fungal diseases might be less clearly detectable.

Present techniques of chlorophyll fluorescence imaging, such as the modular system of FluorCam MF700 (Photon Systems Instruments, Brno, Czech Republic), used under field conditions for head blight detection (measured parameter $\mathrm{F}_{\mathrm{v}} / \mathrm{F}_{\mathrm{m}}$ ) certainly requires adaptations for this particular application [40] (Figure 3). Furthermore, changing photon fluence rates and direct exposure to sunlight should be avoided during measurement, while recording of $F_{0}$ and $F_{m}$ requires dark adaption (approx. $10 \mathrm{~min}$; [50]) of plants [13,46,51]. If these requirements are fulfilled, CFI can be successfully applied even under outdoor conditions [40] (Figure 4). 
Figure 3. CFI measurements for on-field evaluation of Fusarium infection in wheat: (a) FluorCAM MF 700; (b) Movable windshield construction for CFI measurements.
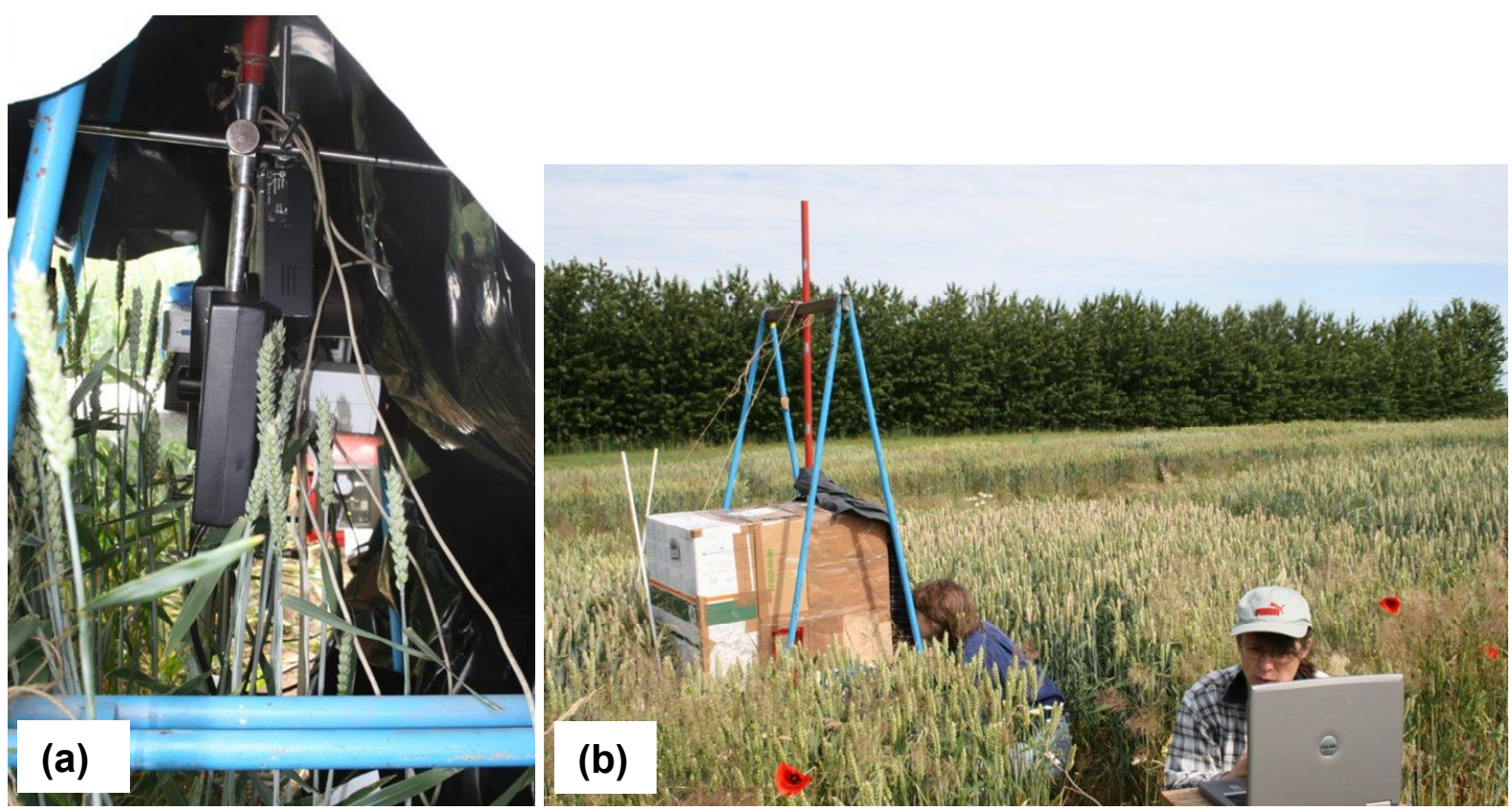

Figure 4. Images of $F_{v} / F_{m}$ distribution on wheat heads infected at largely different degrees.

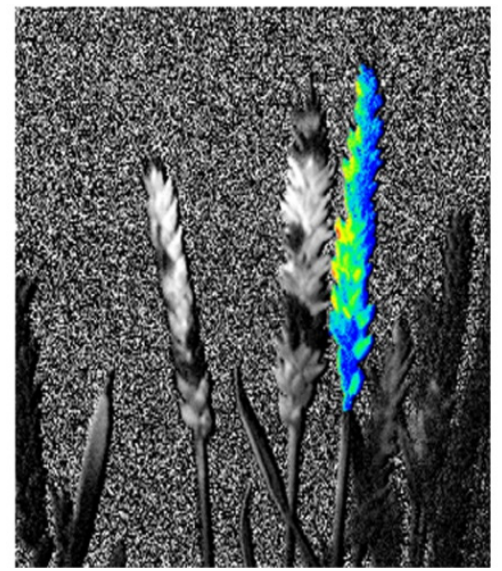

degree of infection: $90 \%$

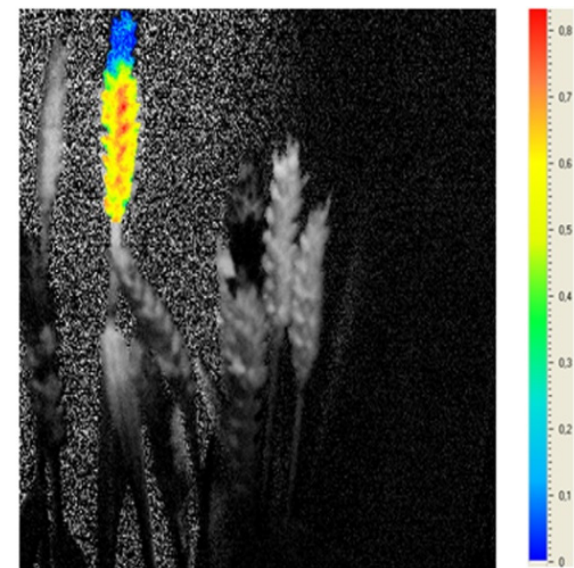

degree of infection: $30 \%$
$F_{v} / F_{M}$ false colour scale

Methodical problems during out-door measurements with current CF imaging systems can be reduced by appropriate usage. Especially difficult are CFI-scans under windy conditions. Because of wheat head movements during records of $F_{0}$ and $F_{m}$ sequences, images of these parameters may not be completely overlaying. The reduction of total recording time to $2 \mathrm{~s}$ may largely reduce this problem. Nevertheless, peripheral areas of heads, worst affected by the wind, can show artificially low $F_{v} / F_{m}$ values and resulting marginal regions of ROIs (ROI = regions of interests) need to be excluded from further analyses. Also, incomplete or uneven shadowing may lead to overestimation of the basic fluorescence and, consequently, incorrectly low $\mathrm{F}_{\mathrm{v}}$. Hence, for out-door usage, measurement techniques and protocols, and algorithms for elimination of outliers need to be optimised to exploit the high potential of CFI for non-invasive disease detection. 


\subsection{Hyperspectral Imaging in the VIS (400-700 nm) and NIR-Range (700-3000 nm)}

Hyperspectral imaging (Figure 5) largely enhances the possibilities of multispectral image analysis. Major advantage of hyperspectral imaging is the pixel-wise incorporation of a continuous spectral signature of hundreds of wavelengths [52] into a two-dimensional image of the object under inspection [53]. This comprises the free choice to calculate ratios of different desired wavelengths (ranges) and of different indices and finally, obtaining multiple wavelengths optimal for evaluation of specific problems under consideration.

Figure 5. (a) Hyperspectral image scanner; (b) Reflexion images of a Fusarium-infected wheat sample at different spectra channels (from left to right: red: $550 \mathrm{~nm}$, green: $685 \mathrm{~nm}$, blue: $765 \mathrm{~nm})$.

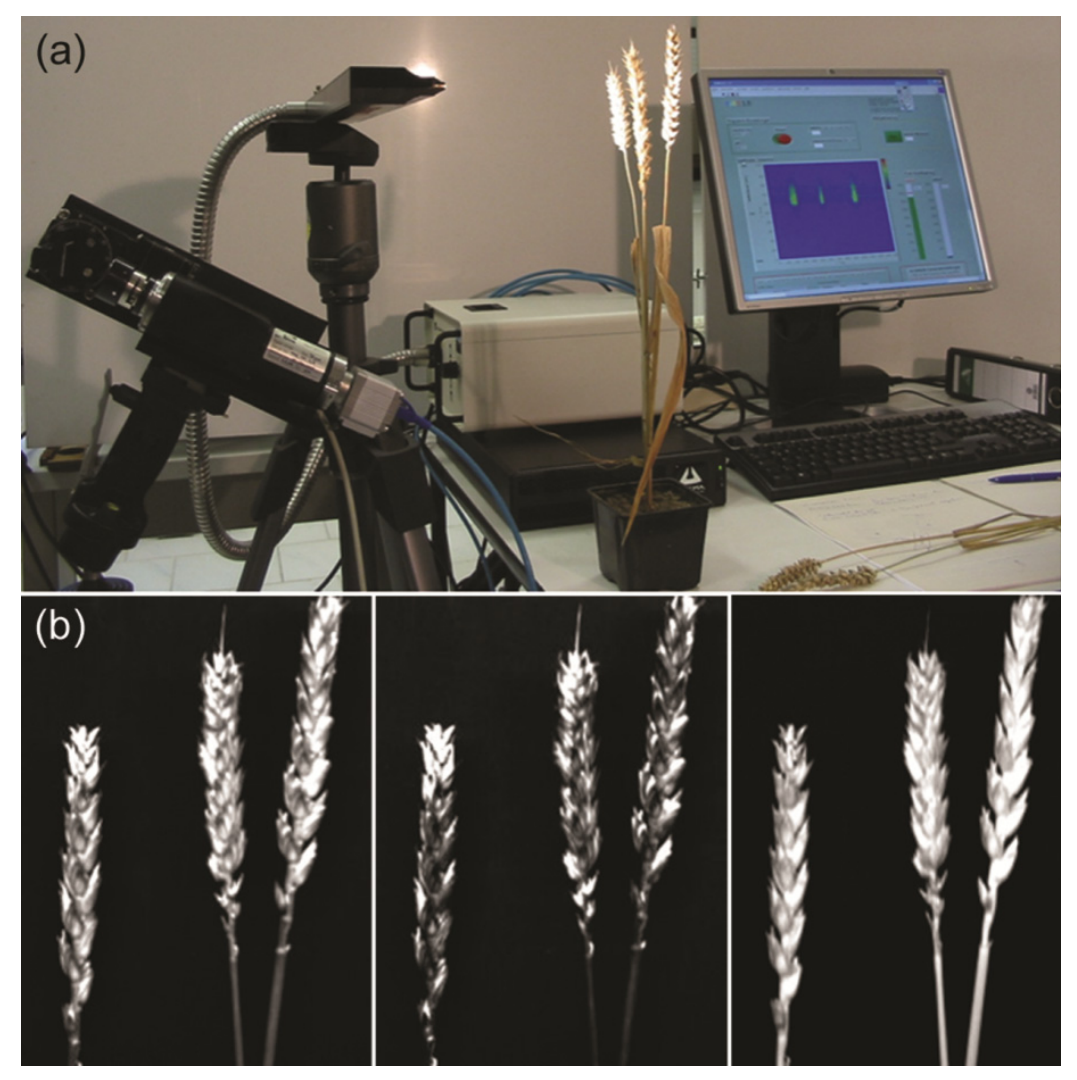

By applying six different vegetation indices, calculated from spectra of sugar beet leaves infected with Cercospora beticola, Erysiphe betae and Uromyces betae, it was possible to distinguish infected and healthy leaves during the course of three weeks [54]. Using discriminant analysis and neuronal networks, 10 optimal wavelengths, out of 167 originally recorded both in the VIS and NIR range, were identified for effective weed detection in sugar beet [55]. For the distinction of various rust pathogens on wheat, different vegetation indices were calculated from spectra recorded between 400 and $900 \mathrm{~nm}$ [56]. While differentiation of yellow rust (Puccinia striiformis $f$. sp. tritici) was fairly simple, the discrimination between $P$. graminis $f$. sp. tritici and $P$. triticina was only possible by several subsequently used indices. 


\subsubsection{Detection of Fusarium-Damaged Grains}

Both symptoms of head blight and also even single Fusarium-damaged spikelets can be detected by hyperspectral imaging. In the VIS to NIR range, six wavelengths were identified by Principal Component Analysis (PCA) and used to detect infected grains by linear discriminant analysis with an accuracy of $92 \%$ [57]. In another investigation, two high resolution hyperspectral imaging systems ("Spectral Dimensions Matrix"-NIR camera with an indium-gallium-arsenic detector; range 960-1662 nm; sisuChema SWIR system with a mercury-cadmium-tellurium detector; range 1000-2500 nm) were used to evaluate Fusarium verticilloides infection in maize [58]. By selecting only few specific wavelengths (1960 and $2100 \mathrm{~nm}$ for infected; 1450, 2300 and $2350 \mathrm{~nm}$ for non-infected grains), discrimination of healthy and infected tissue was possible with both systems (Matrix-NIR, $r^{2}=0.73$; SWIR, $r^{2}=0.86$ ). The infection-related spectral alterations in the wavelengths ranges of 1360 to $1600 \mathrm{~nm}$ and 1960 to $2100 \mathrm{~nm}$ are assumed to reflect changes in hosts' carbohydrate and protein contents and compositions [59]. Analyzing differences in the red and green spectral range between healthy and diseased grains [60] could identify abnormalities of Fusarium damaged kernels. Even with fewer wavelengths and less technical affords Fusarium-infected kernels could be detected with a high probability (90\%). [61] found a significant correlation between the colour components hue, saturation and intensity (HSI) of RGB images and the thousand-seed-weight, which decreased with infection.

From NIR spectra (940 to $1700 \mathrm{~nm}$ ) and applying a classification, which regards grain mass and the differences in logarithmic reciprocal spectral values at 1182 and $1242 \mathrm{~nm}$, Fusarium damaged wheat grains could be detected by hyperspectral imaging with an accuracy of up to $95 \%$ under practical conditions [2]. [59,62] used absorption spectra in the NIR range to determine the Deoxynivalenol (DON) content in Fusarium infected kernels. Following acetonitrile extraction, DON contaminated wheat grains showed mycotoxin content-depended spectral differences at 1204, 1365 and $1700 \mathrm{~nm}$. Significant spectral differences between DON free and DON contaminated material appeared in the ranges between 1425 to $1440 \mathrm{~nm}$ and 1915 to $1930 \mathrm{~nm}$ [59]. It, however, remains uncertain to what extent different fungal diseases of grains are distinguishable by NIR. Penecillium spp. and Aspergillus species, for instance, show abnormalities at similar wavelengths (1284, 1316, $1347 \mathrm{~nm})$ as Fusarium [63]. Furthermore, carbohydrates, proteins and lipid contents of infected tissues are probably likewise modified in all these fungal diseases. [64] applied hyperspectral transmission imaging with an ImSpector spectrograph (Spectral Imaging Ltd., Oulu, Finland) in both VIS and NIR range to link the spectral information to the kernels' content of Fusarium culmorum DNA by supervised partial least squares regression. As stated for CFA, in particular the combination of the spectral information and its spatial distribution patterns obtained by imaging in the examined object largely facilitates the detection of plant diseases or tissue damages [65].

\subsubsection{Application of Hyperspectral Imaging for Head Blight Detection}

\subsubsection{Wavelength Ranges for a Successful Discrimination of Head Blight and Other Diseases}

Fusarium infections pronouncedly alter the external appearance of contaminated wheat heads. Early occurrence of senescence symptoms such as chlorophyll degradation and decreased kernel water content [42] indicates the dieback of individual spikelets, which can be readily established by spectral 
analysis. Spectral patterns of healthy and diseased wheat heads mainly differ in the VIS and short wave NIR range between 400 and $1000 \mathrm{~nm}$. The spectral modifications during disease development are based on changes in carotenoid (500 to $533 \mathrm{~nm}$ ) and, in particular, of chlorophyll contents (560 to $675 \mathrm{~nm}$ and 682 to $733 \mathrm{~nm}$ ). Additionally, spectral changes between 927 and $931 \mathrm{~nm}$ represent differences in the water content of healthy and diseased plant tissues. Although plant physiological responses are reflected in all distinct wavelength ranges, the application of mathematical and statistical methods such as interpolation, smoothening, standardization or formation of differences is necessary to provide a solid basis for all calculations and a comprehensive image analysis.

Various indices are used for spectral analysis and imaging. The most common index for characterization of chlorophyll content and "activity" is the so called "Normalized Difference Vegetation Index" (NDVI). The NDVI is mainly helpful for the detection of healthy, chlorophyll containing plants. Consequently, this index does not necessarily give reasonable results for Fusarium detection. The same pertains to other frequently used indices such as "greenness-band" $\left(\mathrm{G}=\mathrm{R}_{554} / \mathrm{R}_{677}\right.$, [66]), the "structure intensive pigment index" (SIPI, [67]), the "normalized pigment chlorophyll index" (NPCI, [68]) or the Lichtenthaler index (Lic1 and Lic2, [69,70]). These are not quite suitable to distinguish healthy from Fusarium infected wheat heads. For instance in case of greenness-band or NPCI, infected tissue parts cannot be explicitly recognized, although, in particular, the chlorophyll free spikelets must be determined for evaluation of Fusarium infection. Furthermore, threshold definition for the successful detection of infected tissues is very difficult for SIPI [45].

In a Fusarium infected wheat head tissue, the absorption in the range of chlorophyll bands decreases rapidly with a progressing infection as a result of the destruction of chloroplasts and the gradual decomposition of chlorophyll in fungus affected cells [41]. The decrease in the chlorophyll content in these cells reduces the potential of the internal photon remission and re-absorption processes in the relevant wavelength range. This leads to a distinct shift (up to $15 \mathrm{~nm}$ ) of the "red edge" inflection point of the spectrum [71] from approximately $700 \mathrm{~nm}$ to shorter wavelengths (Table 1).

All modifications described above become more distinct with an increasing degree of infection. [72] reported enhanced flattening of the green reflexion peak and a strong decrease of reflexion at near infrared wavelengths with increasing degree of disease $(0.6 \%, 5.2 \%, 49.2 \%, 76.1 \%)$ of Drechslera tritici-repenti infected summer wheat leaves. Additionally, these authors found a similar decrease in the near infrared reflexion plateau with an increasing degree of infection of the examined leaves accompanied by an enhanced reflexion in the visible range $(550-750 \mathrm{~nm})$.

To detect exactly those heads that are head blight diseased, [40] suggested to analyze the records with the head blight index (HBI) that needed only two spectral ranges comprising a band of $10 \mathrm{~nm}$ each (665-675 and 550-560 nm). These two ranges reflect modifications of major photosynthetic pigments (chlorophylls and carotenoids) and effectively indicate infection induced physiological damages. As a result, both ranges show by far the most distinct modifications of the spectral signature. Utilizing the HBI, the data collection can be technically less complex and its evaluation can be much quicker. Therefore, the HBI could be an index for an early detection of a Fusarium infection, although it is slightly less efficient than the spectral angle mapper algorithm (SAM) that uses much more bands. Approximately $84 \%$ of healthy and infected tissue was found in the error range of $+/-10 \%$. This error range seems to be acceptable as the rating error is of the same dimension [73]. The visual rating is always subjective and the rate of error could thus strongly depend on the personal skills of the rating 
person. On the other hand, the actual infection in the field is rated three-dimensionally because the head is looked upon as a whole [73]. Image analysis, however, displays the object only two-dimensionally. Due to the loss of one dimension, the accuracy of the image analysis may suffer.

Table 1. Summary of some plant-pathogen systems, the spectral lines used for analysis and information about targets and statistical methods of analyses.

\begin{tabular}{|c|c|c|c|}
\hline Plant-Pathogen system & Relevant Spectral Lines & Targets/Method & References \\
\hline Triticum aestivum-Fusarium & $\begin{array}{l}550-560 \mathrm{~nm} \\
665-675 \mathrm{~nm}\end{array}$ & $\begin{array}{l}\text { detection of carotenoids } \\
\text { and chlorophylls }\end{array}$ & {$[38]$} \\
\hline $\begin{array}{c}\text { Beta vulgaris-Cercospora } \\
\text { beticola, Erysiphe betae and } \\
\text { Uromyces betae }\end{array}$ & $\begin{array}{l}10 \text { optimal wavelengths } \\
\text { between } 450-1650 \mathrm{~nm}\end{array}$ & & {$[55]$} \\
\hline $\begin{array}{l}\text { Triticum aestivum-Puccinia } \\
\text { striiformis } f \text {. sp. tritici, } \\
\text { P. graminis } f \text {. sp. tritici and } \\
\text { P. triticina }\end{array}$ & indices & & {$[56]$} \\
\hline $\begin{array}{l}\text { Zea mays-Fusarium } \\
\text { verticilloides (grains) }\end{array}$ & $\begin{array}{l}1960 \text { and } 2100 \mathrm{~nm} \text { for infected; } \\
1450,2300 \text { and } 2350 \mathrm{~nm} \text { for } \\
\text { non-infected grains }\end{array}$ & $\begin{array}{l}\text { changes of carbohydrate } \\
\text { and protein contents }\end{array}$ & {$[58]$} \\
\hline $\begin{array}{c}\text { Triticum aestivum-Fusarium } \\
\text { (grains) }\end{array}$ & RBG & & [61] \\
\hline $\begin{array}{c}\text { Triticum aestivum —Fusarium } \\
\text { (grains) }\end{array}$ & 1182 and $1242 \mathrm{~nm}$ & & {$[2]$} \\
\hline $\begin{array}{c}\text { Triticum aestivum-Fusarium } \\
\text { (grains) }\end{array}$ & 1425 to $1440 \mathrm{~nm}$ and 1915 to $1930 \mathrm{~nm}$ & $\begin{array}{l}\text { DON estimation changes } \\
\text { of carbohydrates, proteins } \\
\text { and lipid contents }\end{array}$ & {$[59]$} \\
\hline $\begin{array}{c}\text { Triticum aestivum-Fusarium } \\
\text { (grains) }\end{array}$ & 1204,1365 and $1700 \mathrm{~nm}$ & $\begin{array}{l}\text { DON estimation changes } \\
\text { of carbohydrates, proteins } \\
\text { and lipid contents }\end{array}$ & {$[62]$} \\
\hline $\begin{array}{c}\text { Triticum aestivum-Penecillium } \\
\text { spp. and Aspergillus species } \\
\text { (grains) }\end{array}$ & $1284,1316,1347 \mathrm{~nm}$ & $\begin{array}{l}\text { changes of carbohydrates, } \\
\text { proteins and lipid contents }\end{array}$ & {$[63]$} \\
\hline $\begin{array}{c}\text { Triticum aestivum-Fusarium } \\
\text { culmorum }\end{array}$ & $430-1750 \mathrm{~nm}$ & method: PLS & [64] \\
\hline $\begin{array}{c}\text { Triticum aestivum-Drechslera } \\
\text { tritici-repenti }\end{array}$ & $550-750 \mathrm{~nm}$ & methods: PCA, FVBA & {$[72]$} \\
\hline $\begin{array}{c}\text { Beta vulgaris-Heterodera } \\
\text { schachtii and Rhizoctonia solani }\end{array}$ & $400-1000 \mathrm{~nm}$ & methods: SVI, SAM & {$[74]$} \\
\hline Triticum aestivum-Fusarium spp. & $670 \pm 22,800 \pm 65 \mathrm{~nm}$ & & {$[12]$} \\
\hline Triticum aestivum-Fusarium spp. & RGB & $\begin{array}{l}\text { changes of chlorophyll } \\
\text { and carotenoids }\end{array}$ & {$[75]$} \\
\hline Triticum aestivum-Fusarium & bands in R, MIR and NIR & $\begin{array}{l}\text { changes of chlorophyll } \\
\text { and carotenoids }\end{array}$ & {$[11]$} \\
\hline
\end{tabular}

Despite these problems, the present approach can rapidly provide valuable information about the degree of Fusarium infection in wheat and can therefore indicate the risk of a mycotoxin 
contamination. On the other hand, visual symptoms of head blight not necessarily reflect detectable contents of mycotoxin. Occurrence and extent of mycotoxin formation depends on various conditions and is variable between species [76]. Even this uncertainty also indicates the great importance of an accurate detection especially in the lower classes of infection.

\subsubsection{Detection Accuracy and Time Frame of the Application of Existing Classification Algorithms}

Depending on the situation of the data, both supervised and unsupervised classification is possible. In unsupervised classifications, different spectral classes are automatically assigned by a computer or a evaluation module, respectively, after specification of certain parameters (e.g., number of classes etc.), This finally yields an assembly of values based on similar statistic attributes, wherein similar pixel values can be combined into one value (algorithms: IsoData, k-means). The different pixels comprise certain grey-scale values and correspond to the colors of the image. On the other hand, if well-defined classes should be distinguished, supervised classification methods such as Minimum Distance, Parallelepiped, Maximum Likelihood, Mahalanobis Distance, Binary Encoding or Spectral Angel Mapper (SAM) may be applied.

The different classification algorithms available for automated identification show very specific advantages. In case of multispectral image analysis with only few wave lengths, good classification results can be achieved by Maximum Likelihood [77,78]. In contrast, Spectral Angle Mapper obtained good classifications with highly complex hyperspectral images [79,80].

In a RGB imaging-based approach to automatically identify Fusarium-infected wheat heads [75], the authors used two supervised classification methods, i.e., Maximum Likelihood [81,82] and SAM. Evaluating RGB images, taken under light and shade, respectively, Maximum Likelihood achieved better classifications than SAM, because only three channels were available. In contrast to RGB, hyperspectral images are based on a large number of spectral bands, thus containing much more information. Here, SAM allows a rapid mapping of spectral similarities $[83,84]$ and provides good classification results in most cases [79]. This method directly compares the similarities of different vectors ("spectral angles") of various distinct classes. Consequently, SAM leads to a more efficient and accurate classification of features in hyperspectral images than Maximum Likelihood for instance. Further, hyperspectral image analysis with SAM does not depend on variability of object illumination.

Thus, SAM may be optimal for classifications under semi-practical conditions [85,86]. Indeed, SAM achieved very good classification results in several studies. On sugar beet, Cercospora leaf spots could be correctly evaluated by up to $98 \%$, while powdery mildew and rust were recognized with accuracies of up to $97 \%$ and $62 \%$, respectively [85]. Considering a rating error of $10 \%$, head blight infection was correctly classified up to $87 \%$ [45]. On the other hand, on wheat leaves, support vector machine (SVM) was more successfully applied for the detection of powdery mildew than SAM [86].

By no means, recording and analysis of the 512 wavelengths requires considerable computing resources. In contrast to laboratory studies, this is still not very practical for on-line on-field applications. Installed on a field vehicle, camera systems must record a great amount of spectral information, which has to be analyzed within seconds by the board PC. Additionally, evaluation of disease specific spectra, in particular the setting of ROIs is very time consuming and difficult to integrate into practical processes. 
Another important problem of disease classification by means of spectral imaging is the choice of a suitable stage of plant development; otherwise, results might become inaccurate. If measurements start at a too early stage, anthers and sterile heads potentially caused by growth disturbances will be classified as diseased. In some cases, classification results could be improved by choosing different specific angular radians in corresponding object classes as well as by manually adjusting the angular radians by means of setting a low value, for instance 0.05 . These specific adjustments, however, renders data evaluations even more time consuming.

With incipient grain ripening, spectra of healthy and diseased heads become very similar. This may largely increase the risk of misclassifications [40]. Unclassified pixels reflect the increase in developmental-regulated degradation of chlorophyll, which appears in healthy heads without the typical disease-specific spectral signature of infected grains. To what extend the utilization of a specific class "ripe, but not Fusarium infected" could improve classifications at this developmental stage remains open.

The SAM classification mode opens possibilities to significantly reduce time and computational efforts considering the entire range of 512 wavelengths. Reduction of the amount of spectral information certainly increase the classification efficiency. Reduced band density indeed considerably shortens computation time; it, however, leads to a less accurate classification. For instance, decreasing the number of spectral bands by $25 \%$ often leads to the overestimation of the degree of disease. This effect is most obvious during grain development e.g., in $\mathrm{BBCH} 75$. However, even if the number of bands is reduced, the hyperspectral analysis initially requires to recording the entire spectrum. Furthermore, the time consuming necessity of setting the ROIs remains. That is why this method with a misclassification rate of up to $37 \%$ is hardly appropriate for practical applications.

\subsubsection{Optimum Stage of Head Development for Disease Detection}

It is very important to choose the correct time frame for the classification of the degree of infection by Fusarium on wheat. During examinations of durum wheat plants using red (R), near infrared (NIR) and mid infrared (MIR) spectral bands, the first significant differences between the spectral signatures of healthy and head blight infected plants were obvious during early grain development one week after flowering (BBCH 73) [11]. Similar observations were made on winter wheat [40,45] and durum wheat [87] with hyperspectral imaging. Infected heads could be distinguished from healthy references only seven days after inoculation and were correctly classified 8-10 dai by Partial Least Squares and Discriminant Analysis (PLSDA).

Also, measurements with a multispectral camera in wheat populations comprising types with different ripening times and sensitivities to Fusarium did not lead to satisfying results [12] in an advanced stage of development of the head during late grain ripening ( $\mathrm{BBCH} 85)$. On the contrary, detection during early grain development and ripening (BBCH stages 75-83) was indeed successful even with this method.

\subsubsection{Effects of Steady and Unsteady Characteristics on the Automated Disease Determination}

Degradation of chlorophyll is a steady characteristic of Fusarium head blight. Red spore covering, however, does not develop constantly and, therefore, cannot constitute an exclusive feature for 
detection of Fusarium infection in image analysis. The effects of red spore covering on head blight disease detection were explicitly examined by [45]. The results showed that spectral evaluation by PCA also classified this additional feature as diseased. Thus, red spore covering did not deteriorate the detectability of Fusarium head blight.

Other fungal pathogens such as Pseudocercosporella herpotrichoides, causing the eyespot disease, and Ophiobolis graminis, which elicits the take-all root disease, might also induce head blight. Unlike Fusarium with its partial chlorophyll defect [88], infections with these fungal pathogens result in chlorophyll defects on the entire head. Chlorophyll fluorescence and hyperspectral imaging (HSI) enables the automated detection of symptoms; it cannot, however, replace the analytical determination of correspondingly generated mycotoxins.

\subsubsection{Effects of the Degree of Infection on the Detection Accuracy of Hyperspectral Imaging}

As in the case of chlorophyll fluorescence imaging, at least a degree of Fusarium infection of 5\% should have developed [38] for effective disease detection with HIS; otherwise even minimal interferences in development and growth might result in serious misclassifications.

Although for hyperspectral imaging detection accuracy is less dependent on the degree of infection, it is much more influenced by the time recording takes place. This is true for both SAM classifications with 512 and 168 bands as well as for disease detection with the head blight index. Applying SAM classification with only 168 bands, misclassification rated up to $37 \%$, which is much too high in relation to the necessary efforts. If all 512 bands are analyzed with SAM, the period between full flowering and late grain development $(\mathrm{BBCH}$ stage 65 to $75 / 77)$ is optimal for head blight detection yielding a misclassification of only approx. $4 \%$.

The hit ratio with $\mathrm{HBI}$ is about $67 \%$ during the whole period between full flowering and final grain ripening (BBCH 65 to 89). Considering the optimal time of classification, detection accuracy of this index is definitely improvable. In the $\mathrm{BBCH}$ stage 65 to $75 / 77$ (i.e., full flowering till mid grain development), HBI achieved very precise detection results with an average absolute deviation of infection of a little over 2\%. Nevertheless, upon final grain ripening (BBCH 85 to 89), deviation of residues increases to nearly $21 \%$ as a result of physiological changes.

\subsection{Advantages and Disadvantages of Chlorophyll Fluorescence and Hyperspectral Imaging for Head} Blight Detection

Radically improved image analysis techniques, and reproducible and reliable data acquisition systems denote the initial vital steps of any attempt to optimize objective disease recognition. Only then a meaningful automatic on-field detection of head-blight will become possible. For non-invasive analysis of head-blight disease on wheat heads, CFI has yet only rarely been used, although this technique seems very well suited for this purpose, in particular during the initial phase of infection. Already on the 6th dai onward, early recognition of Fusarium infection was possible with CFI but not with hyperspectral imaging [40]. $\mathrm{F}_{\mathrm{v}} / \mathrm{F}_{\mathrm{m}}$, the parameter applied in the above study, indicates overall photosynthetic activity and closely reflects the intactness of the entire photosynthetic apparatus [50]. Hence, $F_{v} / F_{m}$ may sensitively monitor the physiological responses of cells to fungal infection, well before any visual symptoms may become detectable [40]. 
Nonetheless, hyperspectral analysis provides its own advantages. Unquestionably, hyperspectral imaging includes a much higher information density than multispectral or RGB images. The involvement of several hundreds of wavelengths in image analysis may provide the prerequisite for high accuracy of detection, and, thus, makes a meaningful monitoring of maturation, quality or diseases possible at all [58,89-92]. Nevertheless, with currently applied standard techniques such as conventional line scanners, recording of hyperspectral images is rather slow $[45,58,74]$. In addition, pre-processing, processing and analyses of the enormous amount of data are, still, laborious and time consuming and, thus, retarding infection evaluation. At the normal on-field operating speed of approx. $10 \mathrm{~km} \mathrm{~h}^{-1}$, disease symptoms cannot be reliably evaluated. On the other hand, recent advances in hyperspectral techniques such as high speed real time imaging system UHD 285 (Cubert GmbH, Ulm, Germany), operating with cube rates of up to $20 \mathrm{~s}^{-1}$, the ever increasing performance and miniaturization of computer and actual improvements of mathematical and statistical image analysis algorithms may render hyperspectral imaging accessible for practical on-field disease monitoring in the near future.

Another limitation for the spectral recognition of head blight disease in the VIS and short-wavelength NIR range (up to $1000 \mathrm{~nm}$ ) on wheat is that it is only meaningful between mid grain development till early grain ripening (BBCH 75 to 83). After full maturation of grains, chlorophyll is completely degraded and tissue water content is decreasing. Hence, any attempt to classify healthy and diseased grains in fully ripe wheat heads by means of spectral imaging beyond $\mathrm{BBCH} 85$ is only reasonable if the NIR range is considered [58]. In this spectral range, infection-induced variations in water and protein contents grains may be estimated. This, in turn, may provide additional valuable information about the true degree of infection and could improve the significance of pre-harvest on-field detection of Fusarium infection.

Technical solutions for the practical implementation of on-line, on-field Fusarium detection during wheat harvest are yet available. One approach would be the automatic separation of healthy and diseased grain batches directly in the grain stream on the harvester. In a yet existing quality-differentiated harvesting of cereals, NIR sensors, continuously acquiring e.g., the protein content of grains, are used to control the direction of the grain stream into the respective grain tanks [93]. In case of Fusarium-contaminated wheat, this on-line grain sorting technique, however, is still not meaningful to apply [94]. This would require the direct analysis of mycotoxins in addition to that of protein and water contents of grains. For this purpose, unfortunately no on-line sensors for mycotoxins exist at the moment.

Hence, the imaging-based on-field pre-harvest detection and monitoring of head blight on wheat is currently the only meaningful technique to potential control the negative impacts of Fusarium infection on grain quality and safety. In combination with GPS data, maps of potential centres of infection can be obtained site-specifically with this approach. Based on this information, the harvester can either simply bypass areas with contaminated crops or, if possible, may separately harvest healthy and potentially infected grains, as discussed above. 


\subsection{Approaches to Analyse Chlorophyll Fluorescence and Spectral Images}

Normally, CF transient measurements are evaluated by averaging the relevant parameters (e.g., $F_{\mathrm{v}} / F_{\mathrm{m}}, \mathrm{NPQ}, \Phi_{\mathrm{PSII}}$ ) over the object under consideration $[25,50,95]$. To follow the course of Plasmopara viticola infection, [96] applied a complex pixel-wise analysis of CF images. Manual setting of ROIs during image analyses may further help to improve quality of disease detection [22].

In some studies on the evaluation of combined CF and thermographic image analyses, resembling and interpolation was applied to link the results of systems providing different spatial resolutions. This approach, indeed, enables the combination of different types of measurement results. Hence, this method was used to quantitatively analyze the local variability of physiological processes on leaf surfaces from images obtained with both techniques [97]. In contrast, [98] used the local distribution patterns of maximum temperature variations between healthy and infected tissues, obtained by thermal imaging, to illustrate the degree of infection of cucumbers with Pseudoperonospora cubensis (downy mildew). The algorithm applied proved to be very sensitive for pathogen detection during the course of the disease.

For automatic detection of stripe rusts on wheat, [99] merged two fluorescence emission images (emission wavelengths 550 and $690 \mathrm{~nm}$ ). Effective wavelengths of fluorescence were chosen out of four initially recorded. From fluorescence image intensities at both wavelength, the authors pixel-wise calculated the disease index $\mathrm{f}_{\mathrm{G}}$ as

$$
f_{G}=\frac{I_{550 \mathrm{~nm}}}{I_{550 \mathrm{~nm}}+I_{690 \mathrm{~nm}}}
$$

They defined values of $f_{G}<0.65$ as indicative for diseased.

Similarly, [100] detected Fusarium infection on seed potatoes by mathematically combination of two fluorescence images, taken at 554 and $649 \mathrm{~nm}$. Respective fluorescence signals from ROIs of healthy and infected tissues were used as data bases for the evaluation program written in MATLAB. As a first step, with an ANOVA, the authors determined an optimal global threshold value at which classification accuracy was highest. As a second step, standard PCA was applied to select multispectral wavebands optimal for disease detection.

From CF images of Tulip Breaking Virus (TBV)-infected tulip plants, [37] calculated means \pm standard deviation of the photochemical efficiency in classes from 0 to 1 individual for each single leaf. Averaging, however, partially levelled the differences existing between healthy and diseased leaf tissues. Thus, error rates of $31 \%$ to $46 \%$ remained worse than expected for this analysis and lower than the accuracy of detection achieved in comparable studies of [38] and [99]. Similarly, [21] could not sufficiently discriminate regions of infected tissues by averaging respective pixels of non-photochemical quenching images. Quite obviously, besides the adequate resolution of recorded images, a pixel-wise analysis and the elaboration of local distribution patterns may yield a more expedient for disease recognition.

For the complex analysis of relevant wavelengths in hyperspectral images, Principal Component Analysis (PCA) or Partial Least Squares regression (PLS) is preferred [101]. On the other hand, various spectral indices (cf. 2.2.2.1, e.g., Greenness-Band [66], Structure Intensive Pigment Index [67], Photochemical Reflectance Index [102], Normalised Pigment Chlorophyll Index, [68] or Lichtenthaler's 
Indices $[69,70])$ calculated from spectral signals of distinct wavelengths, can be specifically selected for a particular problem and may largely facilitate evaluation.

Furthermore, images obtained by hyperspectral analysis can be evaluated and assessed by supervised and unsupervised classification techniques such as decision tree or k-nearest neighbor [103] and Bayes classification or maximum posterior classification [104].

If high-resolution spectral imaging systems are used, which are mainly applied in the laboratory, certain form factors may be integrated in data evaluation. For instance, progressing head blight on wheat is characterized by the close coexistence of parts of the heads comprising dead, chlorophyll free as well as living, chlorophyll containing groups of spikelets. These pronounced local variations in distinct regions of the entire structure under consideration, i.e., the wheat head, may provide valuable additional information that may sharpen recognition efficiency. In that way, [91] used spatial patterns of relative proportions of chlorophyll a and $b$, respectively, along a leaf transect to discriminate areas of frost damages. In general, the pixel-wise classified spectral data may be submitted to additional classification according to size and form patterns. This also may enhance success of discrimination of infected and healthy tissue areas. Applying this idea, [105] sought to improve results of disease recognition with spectral imaging on differentially colored leaves by combining form parameters (length, width, depth of the object), number of pixels and average signal intensities. In addition, by penalized likelihood warping, [48] successfully aligned incongruent CF images of Xanthomonas campestris pv. campestris infected leaves of black nightshade (Solanum nigrum L.). This enabled the authors to rapidly detect the fungal disease. For Fusarium recognition on wheat, [12], by manual calibration, set thresholds that allowed the elimination of misclassified pixels and of small sized clusters. The threshold was set when symptoms in the binary image aligned with those perceived by human eye.

\subsection{Improvement of Disease Recognition by Sensor Fusion}

Mainly by direct fusion of several differing techniques, i.e., in this case of different imaging systems, the efficacy of disease recognition may be further enhanced. As stated earlier, [46] took this step for investigation of stripe rusts on wheat. The weak point in their spectral analysis laid in the accuracy of detection of infected tissues, which were approx. $13 \%$ falsely classified. In contrast, with CFI, $29 \%$ of healthy leaves were misclassified. Combining both techniques in one device that also guaranteed integrated and congruent images reduced classification errors to less than 5\%. Nevertheless, both spectral and CF images (at 550 and $690 \mathrm{~nm}$ ) were still evaluated separately and needed various preprocessing steps (e.g., quadratic discriminant analysis) before they were included in a common data pool for final evaluation. For such complex data analyses, the application of artificial neural networks may provide further improvement of detection results. With this method, [106] could increase detection success of stripe rusts infection on wheat to nearly $99 \%$.

Hence, this approach certainly will also enhance efficiency and accuracy of detection of Fusarium infection on wheat. Fusion of $\mathrm{CF}$ and (multi)spectral imaging may not only provide advances in reduction of detection error rates but may also improve earliness of disease recognition. In this context, CFI has been shown to detect effects of Fusarium infection earlier than spectral reflection imaging [40,45]. Hyperspectral imaging is only effective after infection symptoms, i.e., chlorophyll degradation, have become visible. Cytological analysis of the exact time-course of Fusarium infection on most recent 
winter wheat cultivars clearly stressed the importance of an early disease detection as major determinant for reasonable development and applications of new pesticides [42]. These chemical should be able to effectively function during initial phases of infection before any damage by spread of hyphae occur.

As time-dependent measurement, CFI restricts the absolute speed of detection. On the other hand, spectral imaging may only be reasonable applied for Fusarium recognition when clear disease symptoms had become visible. If both techniques could be used for a direct combined recording of inoculated, infected and diseased wheat heads, respectively, and the resulting sets of data jointly analyzed, the accuracy of Fusarium detection will largely increase, as has been shown by [46]. Appling such a fused sensor system, an overall timeframe of 10 days for meaningful detection of this fungal disease may be feasible [11,40].

Nevertheless, for any imaging-based on-field recording of head blight in a very early stage of fungal infection, at least two passages over crop will be necessary, irrespective of imaging systems were used singularly or fused. The final nitrogen fertilizer application will occur right before heading dates of wheat, while the last dates for pesticide application against rust and Fusarium pathogens are suited between early and late flowering (BBCH 61 to 69) [107]. Cultural and disease management practices are no longer meaningful during late grain development (BBCH 75 to 77) when visible or imaging-based disease detection can be successful. All the more, the construction of imaging analysis-aided GPS-based grain disease risk map and its successful application for a direct split-harvest will certainly help to reduce the risk of grain contamination with Fusarium toxins.

\section{Acknowledgments}

Our studies included in this review were supported by grants of the German Federal Ministry of Education and Research (project ProSenso.net2, BMBF 0339992) and by the Federal Office for Agriculture and Food (FKZ 313-06.01-28-1). Furthermore, the authors thank Katrin Witzke for excellent technical assistance.

\section{Author Contributions}

Elke Bauriegel and Werner B. Herppich equally contributed to this paper.

\section{Conflicts of Interest}

The authors declare no conflict of interest.

\section{References}

1. Shaner, G.E. Epidemiology of Fusarium Head Blight of Small Grain Cereals in North America. In Fusarium Head Blight of Wheat and Barley; Leonard, K.J., Bushnell, W.R., Eds.; APS Press: St. Paul, MN, USA, 2005; pp. 84-119.

2. Delwiche, S.R. Classification of scab- and other mold-damaged wheat kernels by near-infrared reflectance spectroscopy. Trans. ASAE 2003, 46, 731-738. 
3. Ragab, W.; Drusch, S.; Kuhlmann, A.; Beyer, M. Characterizing effects of fermentation and baking on the deoxynivalenol content of rolls. J. Appl. Bot. Food Qual. 2005, 79, 197-201.

4. DLG-Arbeitsgruppe "Mykotoxine". Mykotoxine vermeiden statt "bekämpfen". Sonderdr. DLG-Mitt. 8. Available onlline: http://www.dlg.org/uploads/media/myko.pdf (accessed on 1 March 2010).

5. Gelderblom, W.C.A.; Jaskiewicz, K.; Marasas, W.F.O.; Thiel, P.G.; Horak, R.M.; Vleggaar, R.; Kriek, N.P.J. Fumonisins-Novel mycotoxins with cancer-promoting activity produced by Fusarium-moniliforme. Appl. Environ. Microbiol. 1988, 54, 1806-1811.

6. Kuiper-Goodman, T. Mycotoxins: Risk assessment and legislation. Toxicol. Lett. 1995, 82/83, 853-859.

7. Massart, F.; Saggese, G. Oestrogenic mycotoxin exposures and precocious pubertal development. Int. J. Androl. 2010, 33, 369-376.

8. Ministerium für Infrastruktur und Landwirtschaft des Landes Brandenburg (MIL). Mykotoxine: Vorkommen und Bekämpfungsstrategien in Brandenburg; Ministerium für Ländl. Entwicklung, Umwelt und Verbraucherschutz des Landes Brandenburg: Brandenburg, Germany, 2004; p. 80.

9. Pestka, J.J.; Smolinski, A.T. Deoxynivalenol: Toxicology and potential effects on humans. J. Toxicol. Environ. Health 2005, 8, 39-69.

10. Thate, A.; Schumann, S.; Hanschmann, G.; Urban, Y. Auftreten von Ährenfusariosen und Mykotoxinen in Sachsen und Ergebnisse der Vor- und Nachernteuntersuchungen von Winterweizen 2007 (Appearance of ear fusariosis and mycotoxins in Saxonia and results of pre- and postharvest investigations on winter wheat 2007). Nachrichtenblatt Dtsch. Pflanzenschutzd. 2008, 60, 117.

11. Laguette, S.; Hollingsworth, C.; Motteberg, C.; MacRae, I. Potentials and Limits of Remote Sensing Data for Detection of Fusarium Head Blight on Hard Red Spring Wheat in Minnesota. In Proceedings of the 7th International Conference on Precision Agriculture and Other Precision Resources Management, Hyatt Regency, Minneapolis, MN, USA, 25-28 July 2004; Mulla, D.J., Ed.; Precision Agriculture Center, University of Minnesota: St. Paul, MN, USA, 2004; pp. 1196-1203.

12. Dammer, K.H.; Moeller, B.; Rodemann, B.; Heppner, D. Detection of head blight (Fusarium ssp.) in winter wheat by color and multispectral image analyses. Crop Protect. 2011, 30, 420-428.

13. Von Willert, D.; Matyssek, R.; Herppich, W. Experimental Plant Ecology: Fundamentals and Applications. In Experimentelle Pflanzenökologie: Grundlagen und Anwendungen; Georg Thieme Verlag: Stuttgart, Germany, 1995; p. 344.

14. Maxwell, K.; Johnson, G.N. Chlorophyll fluorescence-A practical guide. J. Exp. Bot. 2000, 51, 659-668.

15. Nedbal, L.; Soukupova, J.; Whitmarsh, J.; Trtilek, M. Postharvest imaging of chlorophyll fluorescence from lemons can be used to predict fruit quality. Photosynthetica 2000, 38, $571-579$. 
16. Herppich, W.B.; Hetz, E.; Dammer, K.-H.; Langner, H.-R.; Beuche, H.; Hellebrand, H.-J. Application of chlorophyll fluorescence imaging analysis in fungal pathogen detection. In Bornimer Agrartechnische Berichte; Institut für Agrartechnik Bornim e.V.: Potsdam, Germany, 2005; Volume 40, pp. 95-108.

17. Daley, P.F. Chlorophyll fluorescence analysis and imaging in plant stress and disease. Can. J. Plant Pathol. 1995, 17, 167-173.

18. Nedbal, L.; Whitmarsh, J. Chlorophyll Fluorescence Imaging of Leaves and Fruits. In Advances in Photosynthesis and Respiration; Papageorgiou, G.C., Govindjee, X., Eds.; Springer: Dordrecht, The Netherlands, 2004; Volume 19, pp. 389-407.

19. Kuckenberg, J.; Tartachnyk, I.; Noga, G. Temporal and spatial changes of chlorophyll fluorescence as a basis for early and precise detection of leaf rust and powdery mildew infections in wheat leaves. Precis. Agric. 2009, 10, 34-44.

20. Rolfe, S.A.; Scholes, J.D. Chlorophyll fluorescence imaging of plant-pathogen interactions. Protoplasma 2010, 247, 163-175.

21. Bonfig, K.B.; Schreiber, U.; Gabler, A.; Roitsch, T.; Berger, S. Infection with virulent and avirulent $P$-syringae strains differentially affects photosynthesis and sink metabolism in Arabidopsis leaves. Planta 2006, 225, 1-12.

22. Buerling, K.; Hunsche, M.; Noga, G. Quantum yield of non-regulated energy dissipation in PSII (Y(NO)) for early detection of leaf rust (Puccinia triticina) infection in susceptible and resistant wheat (Triticum aestivum L.) cultivars. Precis. Agric. 2010, 11, 703-716.

23. Chaerle, L.; Hagenbeek, D.; de Bruyne, E.; Valcke, R.; Van Der Straeten, D. Thermal and chlorophyll-fluorescence imaging distinguish plant-pathogen interactions at an early stage. Plant Cell Physiol. 2004, 45, 887-896.

24. Chaerle, L.; Hagenbeek, D.; de Bruyne, E.; Van Der Straeten, D. Chlorophyll fluorescence imaging for disease-resistance screening of sugar beet. Plant Cell Tissue Organ Cult. 2007, 91, 97-106.

25. Prokopova, J.; Spundova, M.; Sedlarova, M.; Husickova, A.; Novotny, R.; Dolezal, K.; Naus, J.; Lebeda, A. Photosynthetic responses of lettuce to downy mildew infection and cytokinin treatment. Plant Physiol. Biochem. 2010, 48, 716-723.

26. Martinez, D.E.; Luquez, V.M.; Bartoli, C.G.; Guiamet, J.J. Persistence of photosynthetic components and photochemical efficiency in ears of water-stressed wheat (Triticum aestivum). Physiol. Plant 2003, 119, 519-525.

27. Wang, X.; Cai, J.; Jiang, D.; Liu, F.; Dai, T.; Cao, W. Pre-anthesis high-temperature acclimation alleviates damage to the flag leaf caused by post-anthesis heat stress in wheat. J. Plant Physiol. 2011, 168, 585-593.

28. Tartachnyk, I.I.; Rademacher, I.; Kuehbauch, W. Distinguishing nitrogen deficiency and fungal infection of winter wheat by laser-induced fluorescence. Precis. Agric. 2006, 7, 281-293.

29. Kuckenberg, J.; Tartachnyk, I.; Schmitz-Eiberger, M.; Noga, G. Early detection of leaf rust and powdery mildew infections on wheat leaves by PAM fluorescence imaging. Precis. Agric. 2007, 8, 515-521. 
30. Robert, C.; Bancal, M.O.; Lannou, C.; Ney, B. Quantification of the effects of Septoria tritici blotch on wheat leaf gas exchange with respect to lesion age, leaf number, and leaf nitrogen status. J. Exp. Bot. 2006, 57, 225-234.

31. Buerling, K.; Hunsche, M.; Noga, G. Use of blue-green and chlorophyll fluorescence measurements for differentiation between nitrogen deficiency and pathogen infection in winter wheat. J. Plant Physiol. 2011, 168, 1641-1648.

32. Matous, K.; Benediktyova, Z.; Berger, S.; Roitsch, T.; Nedbal, L. Case study of combinatorial imaging: What protocol and what chlorophyll fluorescence image to use when visualizing infection of Arabidopsis thaliana by Pseudomonas syringae? Photosynth. Res. 2006, 90, $243-253$.

33. Buschmann, C.; Bilke, S.; Butterer, A.; Enk, A.; Längle, T.; Wenzel, O.; Lichtenthaler, H.K. Einfluß von Trockenstreß auf die Photosyntheseaktivität verschiedener Ökotypen der Buche (Fagus sylvatica L.) -Unterschiede in der Trockenstressempfindlichkeit. In Berichtsreihe zum Statusseminar der Baden-Württemberg-Projektträgerschaft "Lebensgrundlage Umwelt und ihre Sicherung” (BW-PLUS), FZKA-BWPLUS 15, Diskussionskreis; Botanisches Institut II, Universität Karlsruhe: Leopoldshafen, Germany, 1999; pp. 1-12.

34. Kitajima, M.; Butler, W.L. Excitation spectra for photosystem-I and photosystem-II in chloroplasts and spectral characteristics of distribution of quanta between 2 photosystems. Biochem. Biophys. Acta 1975, 408, 297-305.

35. Pinto, L.S.R.C.; Azevedo, J.L.; Pereira, J.O.; Vieira, M.L.C.; Labate, C.A. Symptomless infection of banana and maize by endophytic fungi impairs photosynthetic efficiency. New Phytol. 2000, 147, 609-615.

36. Murchie, E.; Lawson, T. Chlorophyll fluorescence analysis: A guide to good practice and understanding some new applications. J. Exp. Bot. 2013, 64, 3983-3998.

37. Polder, G.; van der Heijden, G.W.A.M.; van Doom, J.; van der Schoor, R.; Baltissen, A.H.M.C. Detection of the Tulip Breaking Virus (TBV) in Tulip Using Spectral and Vision Sensors. In Proceedings of the 7th European Conference on Precision Agriculture (Precision Agriculture'09); Wageningen, NL, 6-8 July 2009; van Henten, E.J., Goense, D., Lokhorst, C., Eds.; Wageningen Academic Publishers: Wageningen, The Netherlands; pp. 219-227.

38. Bauriegel, E.; Giebel, A.; Herppich, W.B. Rapid Fusarium head blight detection on winter wheat ears using chlorophyll fluorescence imaging. J. Appl. Bot. Food Qual. 2010, 83, 196-203.

39. Häuser-Hahn, I. Focus on Fusarium at BCS Research \& Development. Presentation at Fusariumsymposium Monheim. Available online: http://www.press.bayercropscience.com/ bcsweb/cropprotection.nsf/id/FS05_FoconFusatBCSRD_EN (accessed on 20 January 2010).

40. Bauriegel, E.; Giebel, A.; Herppich, W.B. Hyperspectral and chlorophyll fluorescence imaging to analyse the impact of Fusarium culmorum on the photosynthetic integrity of infected wheat ears. Sensors 2011, 11, 3765-3779.

41. Kang, Z.S.; Buchenauer, H. Cytology and ultrastructure of the infection of wheat spikes by Fusarium culmorum. Mycol. Res. 2000, 104, 1083-1093. 
42. Brown, N.A.; Urban, M.; van de Meene, A.M.; Hammond-Kosack, K.E. The infection biology of Fusarium graminearum: Defining the pathways of spikelet to spikelet colonisation in wheat ears. Fungal Biol. 2010, 114, 555-571.

43. Förschler, A.; Portz, C.; Steiner, U.; Schmitz-Eiberger, M.; Noga, A. Minderung von pilzlichem Pathogenbefall im organischen Obstbau durch Zufuhr von Antioxidantien, Schriftenreihe des Lehr- und Forschungsschwerpunktes USL; Landwirtschaftliche Fakultät der Universität Bonn: Bonn, Germany, 2003; Volume 113, pp. 1-41.

44. Bauer, H.; Plattner, K.; Volgger, W. Photosynthesis in Norway spruce seedlings infected by the needle rust Chrysomyxa rhododendri. Tree Physiol. 2000, 20, 211-216.

45. Bauriegel, E.; Giebel, A.; Geyer, M.; Schmidt, U.; Herppich, W. Early detection of Fusarium infection in wheat using hyper-spectral imaging. Comput. Electron. Agric. 2011, 75, 304-312.

46. Bravo, C.; Moshou, D.; Oberti, R.; West, J.; McCartney, A.; Bodria, L.; Ramon, H. Foliar disease detection in the field using optical sensor fusion. Agric. Eng. Int. 2004, 6, 1-14.

47. Polder, G.; Heijden, G.; Doorn, J.; Baltissen, T. Automatic detection of tulip breaking virus (TBV) in tulip fields using machine vision. Biosyst. Eng. 2014, 117, 35-42.

48. Polder, G.; van der Heijden, G.; Jalink, H.; Snel, J. Correcting and matching time sequence images of plant leaves using penalized likelihood warping and Robust Point Matching. Comput. Electron. Agric. 2007, 55, 1-15.

49. Jalink, H.; van der Schoor, R.; Schapendonk, A.H.C.M. A Method and a Device for Making Images of the Quantum Efficiency of the Photosynthetic System with the Purpose of Determining the Quality of Plant Material and a Method and a Device for Measuring, Classifying and Sorting Plant Material. Patent WO2004040274, The Netherlands, 13 May 2004.

50. Herppich, W.B.; Foerster, J.; Zeymer, J.; Geyer, M.; Schlüter, O. Chlorophyll fluorescence image analysis for non-destructive monitoring of physiological changes in fresh and fresh-cut produce. In Environmentally Friendly and Safe Technologies for Quality of Fruit and Vegetables; Nunes, C., Ed.; Universidade do Algarve: Faro, Portugal, 2012; pp. 45-51.

51. Petkova, V.; Denev, I.D.; Cholakov, D.; Porjazov, I. Field screening for heat tolerant common bean cultivars (Phaseolus vulgaris L.) by measuring of chlorophyll fluorescence induction parameters. Sci. Hortic. 2007, 111, 101-106.

52. Firtha, F.; Fekete, A.; Kaszab, T.; Gillay, B.; Nogula-Nagy, M.; Kovacs, Z.; Kantor, D.B. Methods for improving image quality and reducing data load of NIR hyperspectral images. Sensors 2008, 8, 3287-3298.

53. Chen, Y.R.; Chao, K.L.; Kim, M.S. Machine vision technology for agricultural applications. Comput. Electron. Agric. 2002, 36, 173-191.

54. Mahlein, A.K.; Steiner, U.; Dehne, H.W.; Oerke, E.C. Spectral signatures of diseased sugar beet leaves. In Proceedings of the 7th European Conference on Precision Agriculture (Precision Agriculture'09); van Henten, E.J., Goense, D., Lokhorst, C., Eds.; Wageningen, NL, 6-8 July 2009; Wageningen Academic Publishers: Wageningen, The Netherlands; pp. 271-278.

55. Nieuwenhuizen, A.; Hofstee, J.; van de Zande, J.; Meuleman, J.; van Henten, E. Classification of sugar beet and volunteer potato reflection spectra with a neural network and statistical discriminant analysis to select discriminative wavelengths. Comput. Electron. Agric. 2010, 73, $146-153$. 
56. Devadas, R.; Lamb, D.W.; Simpfendorfer, S.; Backhouse, D. Evaluating ten spectral vegetation indices for identifying rust infection in individual wheat leaves. Precis. Agric. 2009, 10, 459-470.

57. Shahin, M.A.; Symons, S.J. Detection of Fusarium damaged kernels in Canada Western Red Spring wheat using visible/near-infrared hyperspectral imaging and principal component analysis. Comput. Electron. Agric. 2011, 75, 107-112.

58. Williams, P.; Manley, M.; Fox, G.; Geladi, P. Indirect detection of Fusarium verticillioides in maize (Zea mays L.) kernels by near infrared hyperspectral imaging. J. Near Infrared Spectrosc. 2010, 18, 49-58.

59. Peiris, K.; Pumphrey, M.; Dowell, F. NIR absorbance characteristics of deoxynivalenol and of sound and Fusarium-damaged wheat kernels. J. Near Infrared Spectrosc. 2009, 17, 213-221.

60. Makkai, G.; Erostyak, J.; Mesterhazy, A. Identification of Fusarium graminearum infection severity of wheat grains by digitally aided spectroscopy. Opt. Eng. 2013, 52, doi:10.1117/1.OE.52.5.057004.

61. Wiwart, M.; Koczowska, I.; Borusiewicz, A. Estimation of Fusarium head blight of Triticale using digital image analysis of gain. In Computer Analysis of Images and Patterns; Skarbek, W., Ed.; Publisher: Warsaw, Poland, 2001; Volume 2124, pp. 563-569.

62. Dowell, F.E.; Ram, M.S.; Seitz, L.M. Predicting scab, vomitoxin, and ergosterol in single wheat kernels using near-infrared spectroscopy. Cereal Chem. 1999, 76, 573-576.

63. Singh, C.B.; Jayas, D.S.; Paliwal, J.; White, N.D.G. Fungal detection in wheat using near-infrared hyperspectral imaging. Trans. ASABE 2007, 50, 2171-2176.

64. Polder, G.; van der Heijden, G.W.M.; Waalwijk, C.; Young, I.T. Detection of Fusarium in single wheat kernels using spectral imaging. Seed Sci. Technol. 2005, 33, 655-668.

65. Nilsson, H.E. Remote-sensing and image-analysis in plant pathology. Annu. Rev. Phytopathol. 1995, 33, 489-527.

66. Zarco-Tejada, P.J.; Ustin, S.L.; Whiting, M.L. Temporal and spatial relationships between within-field yield variability in cotton and high-spatial hyperspectral remote sensing imagery. Agron. J. 2005, 97, 641-653.

67. Peñuelas, J.; Baret, F.; Filella, I. Semiempirical indexes to assess carotenoids chlorophyll-A ratio from leaf spectral reflectance. Photosynthetica 1995, 31, 221-230.

68. Peñuelas, J.; Gamon, J.A.; Fredeen, A.L.; Merino, J.; Field, C.B. Reflectance indexes associated with physiological-changes in nitrogen-limited and water-limited sunflower leaves. Remote Sens. Environ. 1994, 48, 135-146.

69. Lichtenthaler, H.K.; Lang, M.; Sowinska, M.; Heisel, F.; Mieh, J.A. Detection of vegetation stress via a new high resolution fluorescence imaging system. J. Plant Physiol. 1996, 148, 599-612.

70. Lichtenthaler, H.K.; Gitelson, A.; Lang, M. Non-destructive determination of chlorophyll content of leaves of a green and an aurea mutant of tobacco by reflectance measurements. J. Plant Physiol. 1996, 148, 483-493.

71. Baret, F.; Guyot, G.; Major, D. Coupled Fluorescence and Reflectance Measurements to Improve Crop Productivity Evaluation; Lichtenthaler, H.K., Ed.; Kluwer Academic Publisher: Dordrecht, The Netherlands, 1988; pp. 319-324. 
72. Muhammed, H.H.; Larsolle, A. Feature vector based analysis of hyperspectral crop reflectance data for discrimination and quantification of fungal disease severity in wheat. Biosyst. Eng. 2003, $86,125-134$.

73. Walther, U.; Flath, K.; Moll, E.; Prochnow, J.; Sachs, E. Methodische Anleitung zur Bewertung der partiellen Resistenz von Sorten bzw. Linien unter Berücksichtigung epidemiologischer Aspekte. Mitteilungen der Biologischen Bundesanstalt für Land und Forstwirtschaft 2000, 374, 9-25.

74. Hillnhuetter, C.; Mahlein, A.K.; Sikora, R.A.; Oerke, E.C. Use of imaging spectroscopy to discriminate symptoms caused by Heterodera schachtii and Rhizoctonia solani on sugar beet. Precis. Agric. 2012, 13, 17-32.

75. Hehmke, M.; Dammer, K.H.; Herppich, W.B.; Hellebrand, J.; Beuche, H.; Rodemann, B. Digital image analysis for detection of head blight (Fusarium spp.) in winter wheat. In Proceedings of the International Symposium. Agricultural Field Trials-Today and Tomorrow, Stuttgart-Hohenheim, Germany, 8-10 October 2007; Bleiholder, H., Ed.; Grauer: Stuttgart, Germany, 2007; pp. 56-61.

76. Miedaner, T.; Schneider, B. Züchtungsstrategien zur Verringerung von Ährenfusariosen und Mykotoxingehalten bei Getreide; Universität Bonn: Bonn, Germany, 2002; pp. 55-67.

77. Castillejo-Gonzalez, L.I.; Lopez-Granados, F.; Garcia-Ferrer, A.; Manuel Pena-Barragan, J.; Jurado-Exposito, M.; Sanchez de la Orden, M.; Gonzalez-Audicana, M. Object- and pixel-based analysis for mapping crops and their agro-environmental associated measures using QuickBird imagery. Comput. Electron. Agric. 2009, 68, 207-215.

78. Yang, F.; Li, J.L.; Gan, X.Y.; Qian, Y.R.; Wu, X.L.; Yang, Q. Assessing nutritional status of Festuca arundinacea by monitoring photosynthetic pigments from hyperspectral data. Comput. Electron. Agric. 2010, 70, 52-59.

79. South, S.; Qi, J.G.; Lusch, D.P. Optimal classification methods for mapping agricultural tillage practices. Remote Sens. Environ. 2004, 91, 90-97.

80. Becker, B.L.; Lusch, D.P.; Qi, J.G. A classification-based assessment of the optimal spectral and spatial resolutions for Great Lakes coastal wetland imagery. Remote Sens. Environ. 2007, 108, 111-120.

81. Richards, J.A.; Jia, X. Supervised Cassification Techniques. In Remote Sensing Digital Image, Analysis; Springer-Verlag GmbH: Heidelberg, Germany, 1999.

82. ENVI.Tutorial: Selected Hyperspectral Methods. Available online: http://www.creaso.com (assessed on 1 July 2010).

83. Yuhas, R.H.; Goetz, F.H.A.; Boardmann, J.W. Discrimination among Semiarid Landscape Endmembers Using the Spectral Angle Mapper (SAM) Algorithm. In Summaries of the Third Annual JPL Airborne Geoscience Workshop; Jet Propulsion Laboratory Publication 92: Pasadena, CA, USA, 1992; pp. 147-149.

84. Kruse, F.A.; Lefkoff, A.B.; Boardman, J.W.; Heidebrecht, K.B.; Shapiro, A.T.; Barloon, P.J.; Goetz, A.F.H. The spectral image-processing system (Sips) - Interactive visualization and analysis of imaging spectrometer data. Remote Sens. Environ. 1993, 44, 145-163. 
85. Mahlein, A.K.; Steiner, U.; Hillnhuetter, C.; Dehne, H.W.; Oerke, E.C. Hyperspectral imaging for small-scale analysis of symptoms caused by different sugar beet diseases. Plant Methods 2012, 8, doi:10.1186/1746-4811-8-3.

86. Mewes, T.; Franke, J.; Menz, G. Spectral requirements on airborne hyperspectral remote sensing data for wheat disease detection. Precis. Agric. 2011, 12, 795-812.

87. Menesatti, P.; Antonucci, F.; Pallottino, F.; Giorgi, S.; Matere, A.; Nocente, F.; Pasquini, M.; D’Egidio, M.G.; Costa, C. Laboratory vs. in-field spectral proximal sensing for early detection of Fusarium head blight infection in durum wheat. Biosyst. Eng. 2013, 114, 289-293.

88. Heitefuss, R.; König, K.; Obst, A.; Reschke, M. Pflanzenkrankheiten und Schädlinge im Ackerbau; DLG-Verlag: München, Germany, 1993; p. 151.

89. Gitelson, A.A.; Gritz, Y.; Merzlyak, M.N. Relationships between leaf chlorophyll content and spectral reflectance and algorithms for non-destructive chlorophyll assessment in higher plant leaves. J. Plant Physiol. 2003, 160, 271-282.

90. Lichtenthaler, H.K. Spektroskopische Eigenschaften von Pflanzen und ihre Nutzung zur Fernerkundung der Vegetation. Fridericiana 1994, 49, 25-45.

91. Nicotra, A.B.; Hofmann, M.; Siebke, K.; Ball, M.C. Spatial patterning of pigmentation in evergreen leaves in response to freezing stress. Plant Cell Environ. 2003, 26, 1893-1904.

92. Polder, G.; van der Heijden, G.W.A.M.; Young, I.T. Spectral image analysis for measuring ripeness of tomatoes. Trans. ASAE 2002, 45, 1155-1161.

93. Risius, H.; Hahn, J.; Korte, H. Die Guten ins Töpfchen-Trennung des Erntegutes nach Qualitätseigenschaften während des Mähdruschs. Neue Landwirtsch. 2008, 11, 52-54.

94. Risius, H.; Hahn, J.; Korte, H. Implementation of Process Analytical Technology (PAT) for the Determination of Product Quality on a Combine Harvester. In Proceedings of the 67 International Conference on Agricultural Engineering LAND.TECHNIK Ag Eng, Hannover, Germany, 6-7 November 2009; pp. 375-380.

95. Forstreuter, M.; Schröder, R.; Herppich, W.B. Chlorophyllfluoreszenzbildanalyse zur raschen Indikation des Befalls von Laub- und Nadelbäumen durch herbivore Insekten (Chlorophyll fluorescence imaging to analyse insect herbivory on broad-leaved and coniferous trees). Comput. Bildanal. Landwirtsch. Workshop 2006, 2006, 26-33.

96. Csefalvay, L.; di Gaspero, G.; Matous, K.; Bellin, D.; Ruperti, B.; Olejnickova, J. Pre-symptomatic detection of Plasmopara viticola infection in grapevine leaves using chlorophyll fluorescence imaging. Eur. J. Plant Pathol. 2009, 125, 291-302.

97. Aldea, M.; Frank, T.D.; DeLucia, E.H. A method for quantitative analysis of spatially variable physiological processes across leaf surfaces. Photosyn. Res. 2006, 90, 161-172.

98. Oerke, E.; Steiner, U.; Dehne, H.; Lindenthal, M. Thermal imaging of cucumber leaves affected by downy mildew and environmental conditions. J. Exp. Bot. 2006, 57, 2121-2132.

99. Bravo, C. Automatic Foliar Disease Detection in Winter Wheat. Ph.D. Thesis, Katholieke Universiteit Leuven, Leuven, Belgium, February 2006; p. 258.

100. Kim, D.; Cho, B.; Lee, Y. Multispectral Imaging Technique for Detection of Fungi-Infected Seed Potatoes Based on Hyperspectral Imagery. In Papers Book; Valencia Conference Centre: Valencia, Spain, 8-12 July 2012; p. C-1183. 
101. Davies, A.M.C.; Fearn, T. Back to basics: The principles of principal component analysis. Spectrosc. Eur. 2005, 16, 20-23.

102. Gamon, J.A.; Penuelas, J.; Field, C.B. A narrow-waveband spectral index that tracks diurnal changes in photosynthetic efficiency. Remote Sens. Environ. 1992, 41, 35-44.

103. Weis, M.; Rumpf, T.; Gerhards, R.; Plümer, L. Comparison of Different Classification Algorithms for Weed Detection from Images Based on Shape Parameters. In Bornimer Agrartechnische Berichte; ATB: Potsdam, Germany, 2009; Volume 69, pp. 53-64.

104. Bauer, S.D.; Korc, F.; Foerstner, W. The potential of automatic methods of classification to identify leaf diseases from multispectral images. Precis. Agric. 2011, 12, 361-377.

105. Polder, G.; van der Heijden, G.; van Doorn, J.; Clevers, J.; van der Schoor, R.; Baltissen, A. Detection of the tulip breaking virus (TBV) in tulips using optical sensors. Precis. Agric. 2010, 11, 397-412.

106. Moshou, D.; Bravo, C.; West, J.; Wahlen, T.; McCartney, A.; Ramon, H. Automatic detection of "yellow rust" in wheat using reflectance measurements and neural networks. Comput. Electron. Agric. 2004, 44, 173-188.

107. Pflanzenschutzdienste der Länder. Brandenburg, Sachsen und Thüringen. Available online: www.tll.de/ainfo/pdf/psab0210.pdf (accessed on 9 July 2011).

(C) 2014 by the authors; licensee MDPI, Basel, Switzerland. This article is an open access article distributed under the terms and conditions of the Creative Commons Attribution license (http://creativecommons.org/licenses/by/3.0/). 